\title{
The strategies of perioperative management in orthopedic department during the pandemic of COVID-19
}

\author{
Hui Zeng ${ }^{1,2^{*}} \mathbb{D}$, Guoqing $\mathrm{Li}^{1,2+}$, Jian Weng ${ }^{1,2+}$, Ao Xiong ${ }^{1,2}$, Chang $\mathrm{Xu}^{3}$, Yifei Yang ${ }^{1}$ and Deli Wang ${ }^{1,2^{*}}$
}

\begin{abstract}
Background: Coronavirus disease 2019 (COVID-19) has broken out and spread rapidly nationwide at the beginning of 2020, which has brought huge impacts to people and work. The current situation of prevention and control is severe and urges guidance for clinicians, especially for medical systems. In the hope of providing a reference and recommendation for the prevention and control of the COVID-19, we carried out research to improve the quality of patient care and prevention during this epidemic.

Methods: All of the staff were trained rapidly to master personal protection in our department. We reviewed the patients' discharged records who underwent surgery in our department during January 1 to March 1, 2019, and January 1 to March 1, 2020. The management of the surgery patients and flow charts were described and analyzed. Post-operation outcomes of the patients include duration, complications, surgical site infection (SSI), system infection, re-operation, and mortality. Both chi-squared test and Student's $t$ test were performed to determine the relationship between the two periods in terms of post-operation outcomes.
\end{abstract}

Results: Descriptive statistics analysis revealed that demographic of the patients between the two periods is similar. We had benefited from the strict flowcharts, smart robot, and protection equipment during the perioperative managements for orthopedic patients. With the help of the strict flow charts and smart equipment, post-operation outcomes of the patients revealed that the rates of the complications and re-operation had been reduced significantly $(p<0.05)$, while duration of operation, SSI, and system infection had no significant difference between two periods $(p>0.05)$. No patient and staff caught COVID-19 infection or mortality during the epidemic.

Conclusions: Our study indicated that medical quality and efficiency were affected little with the help of strategies described above during the epidemic, which could be a reference tool for medical staff in routine clinical practice for admission of patients around the world. What is more, the provided strategies, which may evolve over time, could be used as empirical guidance and reference for orthopedic peers to get through the pandemic and ensure the normal operation of the hospital.

Keywords: Coronavirus disease 2019 (COVID-19), Orthopedic surgery, Perioperative management, Flow chart

\footnotetext{
*Correspondence: zenghui_36@163.com; wangdelinavy@163.com

${ }^{\dagger}$ Guoqing Li and Jian Weng contributed equally to this work and are listed as cooperating first authors.

'Department of Bone \& Joint Surgery, Peking University Shenzhen Hospital, Shenzhen 518036, People's Republic of China

Full list of author information is available at the end of the article
}

\section{$\triangle B M C$}

(c) The Author(s). 2020 Open Access This article is licensed under a Creative Commons Attribution 4.0 International License, which permits use, sharing, adaptation, distribution and reproduction in any medium or format, as long as you give appropriate credit to the original author(s) and the source, provide a link to the Creative Commons licence, and indicate if changes were made. The images or other third party material in this article are included in the article's Creative Commons licence, unless indicated otherwise in a credit line to the material. If material is not included in the article's Creative Commons licence and your intended use is not permitted by statutory regulation or exceeds the permitted use, you will need to obtain permission directly from the copyright holder. To view a copy of this licence, visit http://creativecommons.org/licenses/by/4.0/ The Creative Commons Public Domain Dedication waiver (http://creativecommons.org/publicdomain/zero/1.0/) applies to the data made available in this article, unless otherwise stated in a credit line to the data. 


\section{Introduction}

Since December 2019, an unexplained type of coronavirus has appeared rapidly in Wuhan followed by bronchitis and pneumonia $[1,2]$. It has been proven that the pathogen was coronavirus disease 2019 (COVID-19), which seriously threatens surgical staff and patients, and challenged the medical community to an unprecedented degree [3]. COVID-19 can induce not only mild to severe respiratory diseases, but also inflammation, high fever, cough, acute respiratory tract infection, and dysfunction of internal organs which may result in death [4]. The World Health Organization (WHO) declared it as a pandemic on 11 March 2020 because of its rapid worldwide spread [5]. The public health emergency caused by the pandemic has resulted in a significant reallocation of health resources with a consequent reorganization of the clinical activities in orthopedic department.

As secondary transmissions have occurred and the speed of transmission is accelerating, there are rising concerns about community infections and the overwhelming majority of cities have launched higher level response [6,7]. The current situation of prevention and control is grim. Some of orthopedics have agreed on possible strategies for the reorganization of orthopedic routine practice and on a set of recommendations that should facilitate the process of rescheduling both inpatient and outpatient activities during the pandemic.

The epidemic of COVID-19 poses new challenges to diagnosis and treatment of the patients with orthopedic diseases [8]. We medical workers are bearing important responsibilities and pressure during the epidemic. Orthopedic surgeons performed the superiority of accurate diagnosis and treatment for patients, summarized how to carry out the clinical practice of orthopedic surgery under the situation of the prevention and control of the COVID19 , and minimized the risk of infection exposure. Reasonable treatment strategies were changed and adopted timely to minimize the adverse effects on the treatment of orthopedic patients during the epidemic.

The staff in our department make every effort in making correct diagnosis and treatment of specialized diseases by optimizing process, providing proper medical advice, and mastering indications of selective, confine, and emergency operation reasonably. Based on the full understanding of the characteristics of orthopedic diseases and COVID-19, in order to summarize and discuss available evidence for orthopedic practices, we provide the highest quality medical services in the form of flow charts as for the regular clinical practice.

\section{Methods}

Study sample and patients

We built a dataset containing 96 patients who underwent operation between January 1 to March 1, 2019, and January 1 to March 1, of 2020. Data were sourced retrospectively from the medical records. Each discharged abstract involved a multitude of variables. Demographics of the patients of the two periods were described and analyzed, and analysis revealed that they are similar (Table 1). Ethical review approval was obtained from the

Table 1 Analysis of patient demographic characteristics of the two periods ( $N=96)$

\begin{tabular}{|c|c|c|c|c|c|}
\hline \multirow[t]{2}{*}{ Categories } & \multirow[t]{2}{*}{ Unit } & \multicolumn{2}{|c|}{$2019(N=50)$} & \multicolumn{2}{|c|}{$2020(N=46)$} \\
\hline & & Count & Percentage & Count & Percentage \\
\hline Patients & Percentage & 50 & $52.08 \%$ & 46 & $47.92 \%$ \\
\hline Age & Year & - & $61.48 \pm 17.77$ & - & $52.11 \pm 21.33$ \\
\hline \multirow[t]{2}{*}{ Gender } & Male & 22 & $22.92 \%$ & 23 & $23.96 \%$ \\
\hline & Female & 28 & $29.17 \%$ & 23 & $23.96 \%$ \\
\hline \multirow[t]{6}{*}{ Diagnosis } & Fracture & 45 & $46.88 \%$ & 41 & $42.71 \%$ \\
\hline & Infection & 1 & $1.04 \%$ & 2 & $2.08 \%$ \\
\hline & Tumor & 0 & 0 & 1 & $1.04 \%$ \\
\hline & Deformity & 1 & $1.04 \%$ & 0 & 0 \\
\hline & Degeneration & 0 & 0 & 1 & $1.04 \%$ \\
\hline & Others & 3 & $3 \%$ & 1 & $1.04 \%$ \\
\hline \multirow[t]{2}{*}{ Anesthetization } & General & 21 & $21.88 \%$ & 11 & $11.46 \%$ \\
\hline & Non-general & 29 & $30.21 \%$ & 35 & $36.45 \%$ \\
\hline \multirow[t]{4}{*}{ ASA class } & 1 & 1 & $1.04 \%$ & 7 & $7.80 \%$ \\
\hline & 2 & 0 & 0 & 1 & $1.04 \%$ \\
\hline & 3 & 38 & $40.58 \%$ & 26 & $27.08 \%$ \\
\hline & 4 & 11 & $11.45 \%$ & 12 & $12.50 \%$ \\
\hline
\end{tabular}


Human Subject Committee at Ethics Committee of Peking University Shenzhen Hospital (Ethics Committee of Peking University Shenzhen Hospital (research) [2020] 013th).

We reviewed many variables noted in the literature, and a set of recommendations and flow charts were created based on a review of the communications for surgeons with knowledge of safety procedures.

We recommend inpatients during hospital stay should be provided with as many instructions as possible to stay in wards. Patients should be evaluated in detail under stable condition to minimize the risk of readmission. It is advisable for us to reduce or reschedule post-discharge controls and implement an adequate system of communication for telemonitoring patients in order to reduce hospital visits.

In the hope of providing a reference and recommendation for the prevention and control for surgeons, we share our experience during the epidemic in the form of flow charts.

\section{Statistics analysis}

Both chi-squared test and Student's $t$ test were performed to determine the relationship between the two periods. For all analyses, $p<0.05$ was considered statistically significant. All statistical analyses were performed on IBM SPSS Statistics (version 23.0).

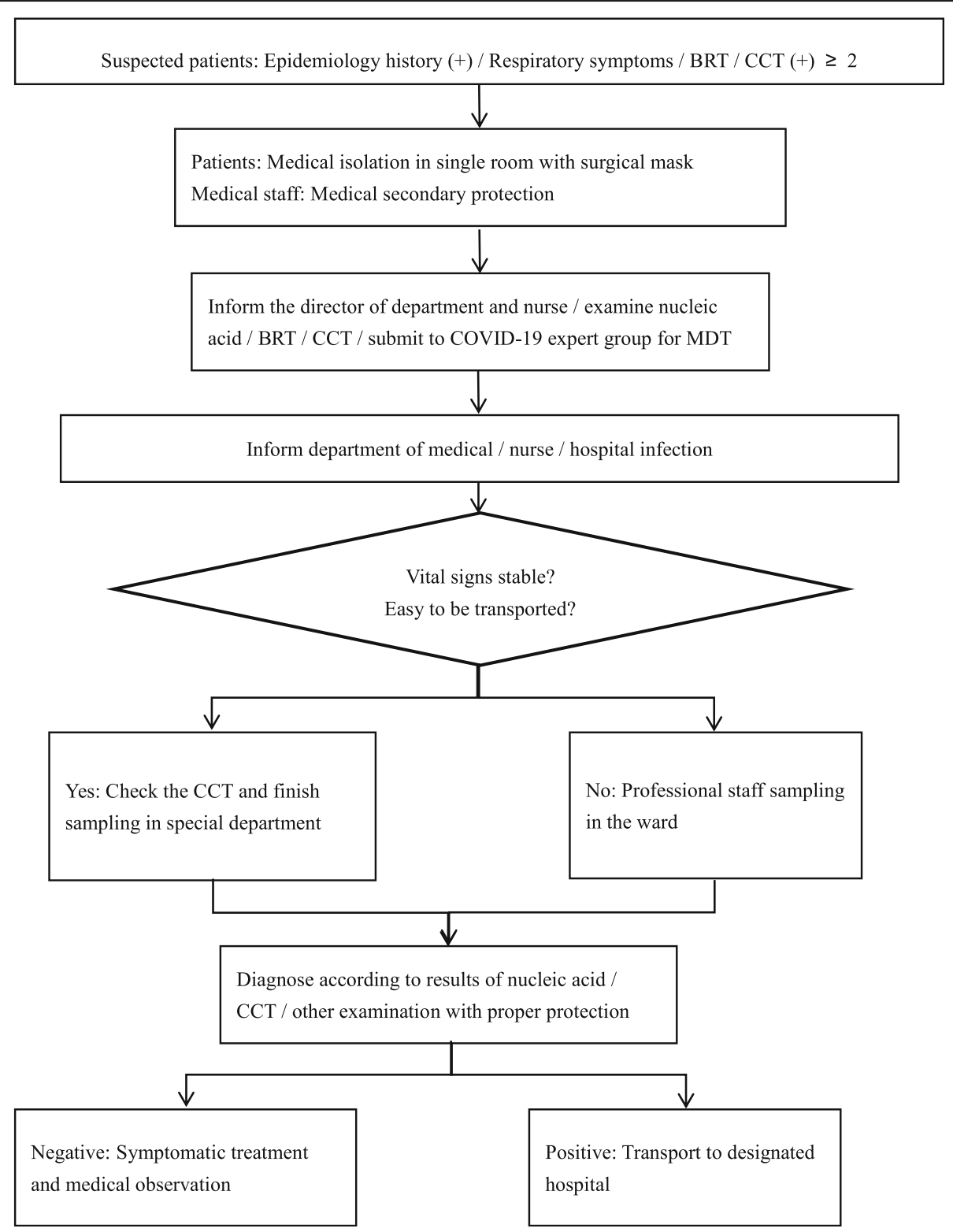

Fig. 1 Flow chart of suspected patient identification 


\section{Practical flow charts}

By summarizing the research progress and guidelines in recent years in the fields of orthopedic diseases, treatment strategies and perioperative management were developed to provide more choices for patients to obtain the best treatment under the severe epidemic. COVID19 brought huge impacts to people and work nationwide; the routine diagnosis and treatment of fractured patients were affected with varied degrees as well.

Instead of traditional diagnosis and treatment, a new system should be developed. Simplification of the diagnostic and staging pathway has to be prioritized in order to reduce hospital visits and consequently the risk of contagion. Orthopedic is not a front-line subject, but fracture is a common injury, and most of the patients are in trouble when diagnosed during the epidemic [9, 10]. The regular diagnosis and treatment of patients were greatly affected, and elective surgical activity of the hospital was rapidly reduced.

Meanwhile, we hope that it could provide more treatment model schemes for colleagues and share the flow charts of management for patients during the breakout of pandemic, including prevention and control measures for staff, operating rooms, and surgical instruments, which may be beneficial for medical staff (Fig. 1). Meanwhile, we prepared workflow for patients who were diagnosed with COVID-19 (Fig. 2).

Moreover, most of parts were involved during the special epidemic. As parts of epidemic response measures, the selection of surgical procedures and perioperative management of orthopedic diseases require all staff to work together to figure out a reasonable system of surgical treatment and emergent response. We concluded experience as following and shared the experiences of the management of patients who are scheduled or emergent to be admitted (Fig. 3).

Some of the surgeons and assistants who come from outside of Shenzhen but ought to enter the OR should obey the special flow chart as well (Fig. 4).

Behavioral assistance robot is withdrawing medicine in the pharmacy (Fig. 5a), which can meet the requirements of a wide variety of clinical drugs and reduce the

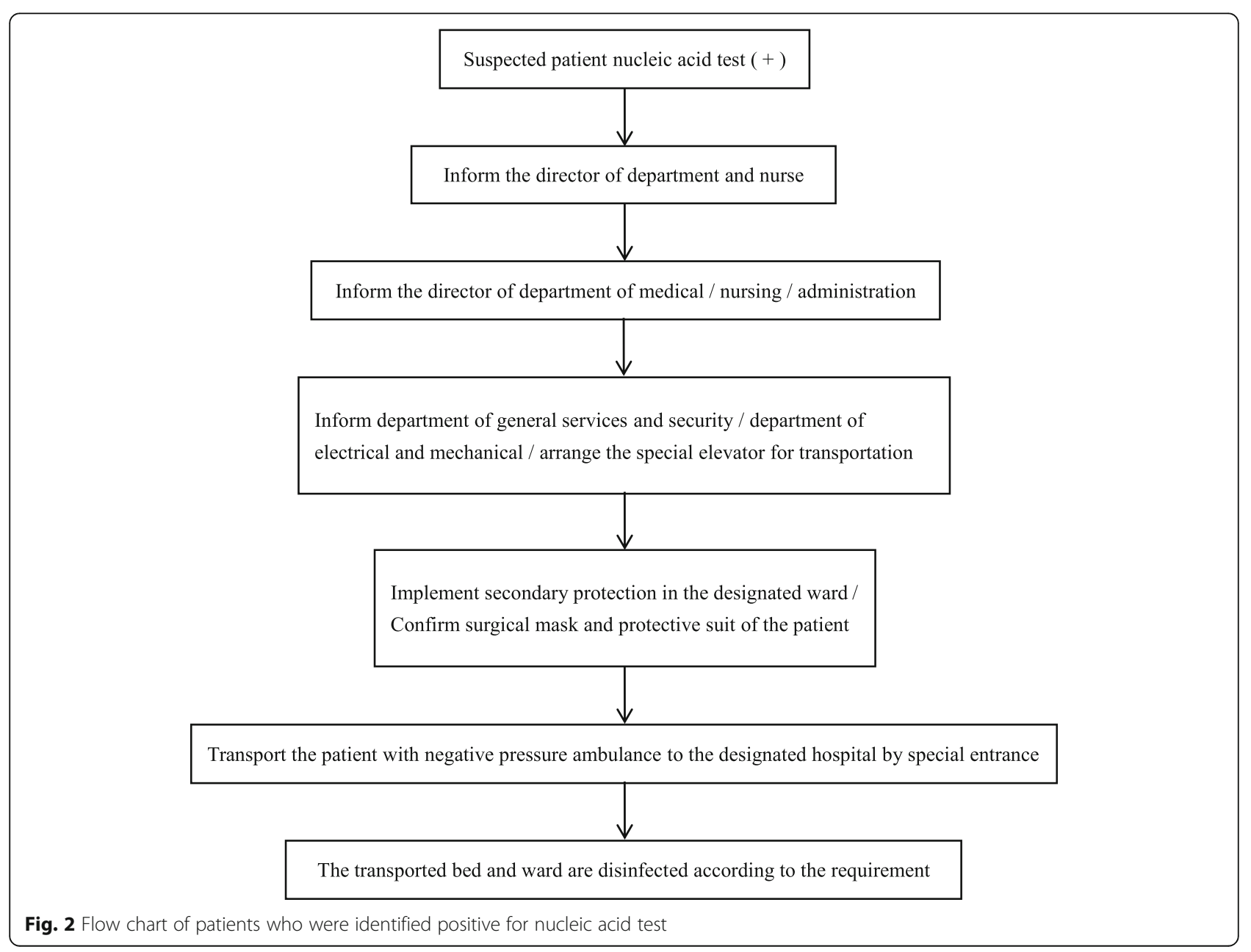


workload or contact and improve the accuracy. Manually monitoring can ensure the entire process is rigorous, accurate, standardized, and safe, which can completely eliminate the inevitable problems of poisoning and pollution in manual operation (Fig. 5b). Nurse assistant robot looks like a cartoon nurse (Fig. 5c), which can assist nurses to complete routine nursing tasks, such as procedure handling, environmental guidance, data query, ward inspections, item delivery, and data printing. Robots transport (Fig. 5d) sterile materials in the OR without touching. Smart assistant robots can help staff in many areas, which are always on call and tireless. With the help of these smart robots, the staff have saved much energy and reduce the contact with patients.

All of the staff were trained rapidly to face the epidemic such as attaching great importance to the personnel protection and implementing the relevant rules and regulations for prevention strictly. One of the personal protection equipment is special surgery hat (Fig. 6a), which can help surgeons reduce the contact and exposure during the operation. Intraoperative photo of selective surgery of total knee arthroplasty (TKA) with special hat is shown in Fig. 6b.

\section{Results}

Analysis for post-operation outcomes of the two periods was displayed (Table 2).

We can tell from the results of the two periods that no staff or patient caught infection of COVID-19 during the epidemic, or no mortality of the two periods. With the help of the strict work flow and smart equipment, the rates of adverse outcomes including complications and re-operation had been reduced significantly compared to the former year $(p<0.05)$, and patients who underwent surgery may have benefited from the work flow during the pandemic. However, duration, SSI, and system

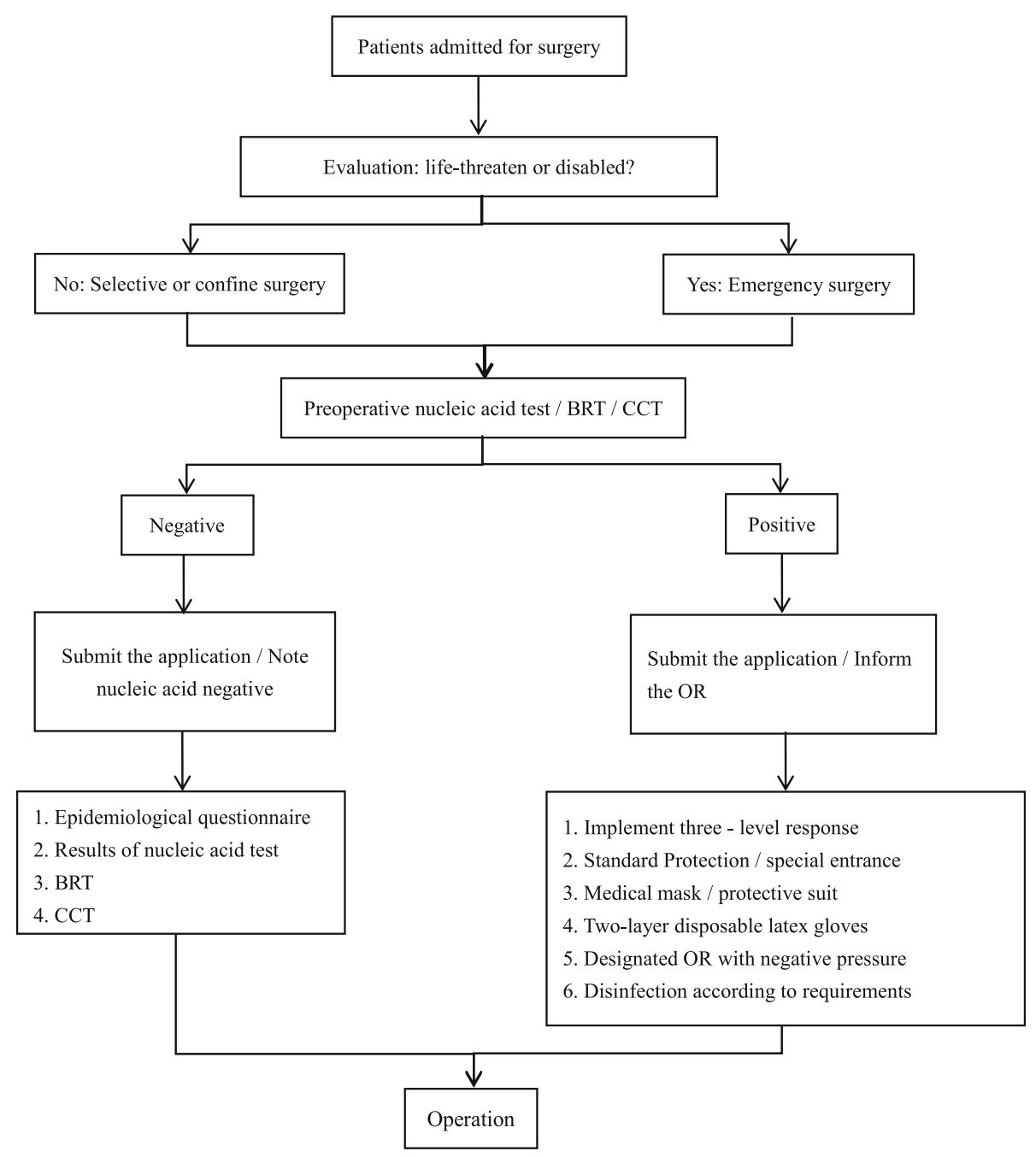

Fig. 3 Flow chart of surgery management for inpatients 


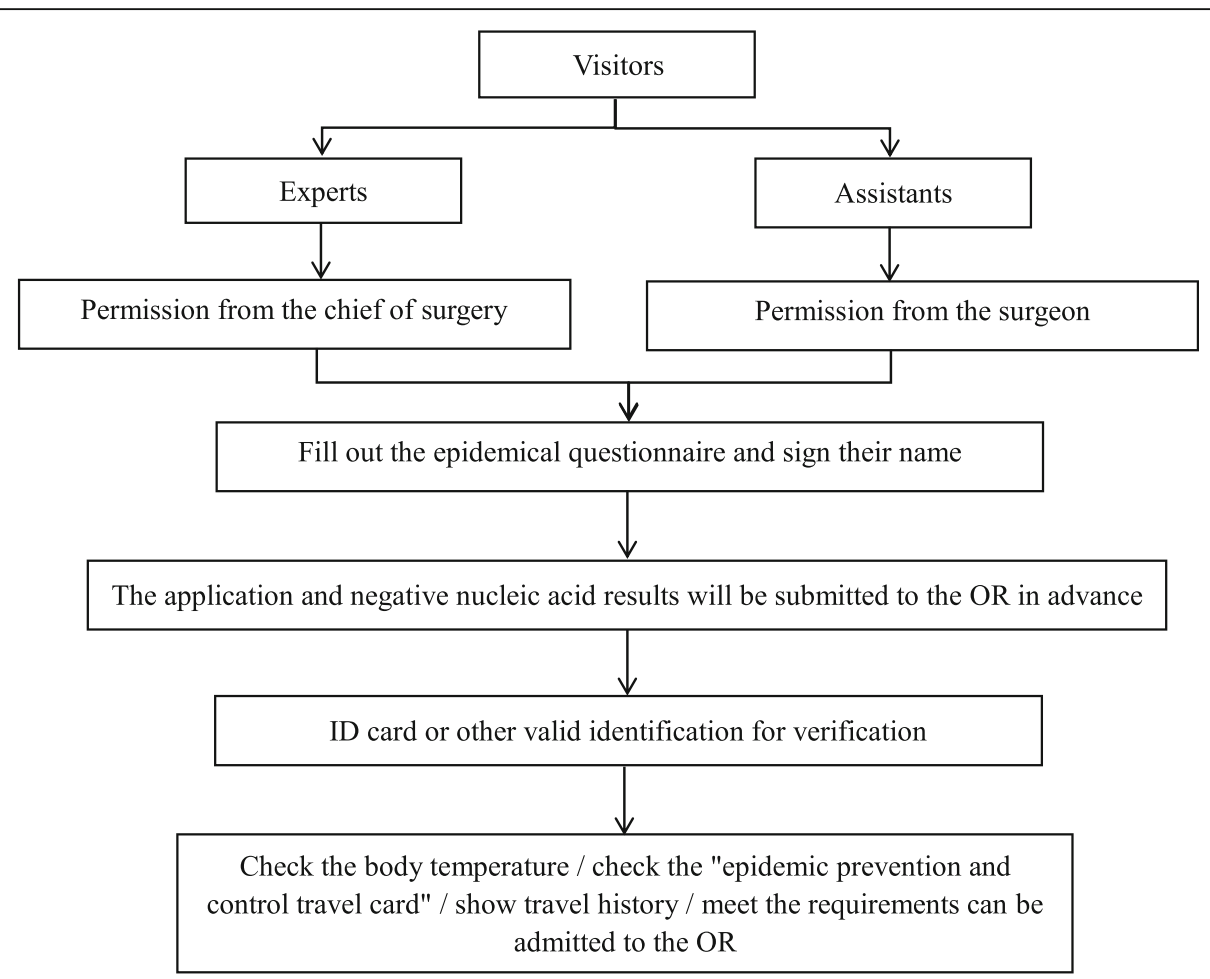

Fig. 4 Flow chart of management for visitors

infection had no significant difference between the two periods $(p>0.05)$.

\section{Discussion}

COVID-19 could result in killing quantities of people, and the current situation of prevention and control is severe. Critical patients are often occures in the old patients who caught multiple comorbidities or lack of health care, which could progress to acute respiratory distress syndrome (ARDS), multi-organ dysfunction (MODS), or even death $[11,12]$. We searched the literature and assessed the certainty in the evidence using the recommendations based on the experience of health care systems in Asia and Europe [13], and recommendations were in the form of best clinical practice. Furthermore, many relevant steps were adopted and clinical activities were carried out to explore new strategies and effective therapies during the epidemic.

It is particularly important to underline the clinical features of COVID-19, especially in the early stage of the illness. Up to now, multiple guidelines have been issued by various organizations to recommend their practice. In relationship with orthopedic diseases during the epidemic, related prevention and control, clinical recommendations,

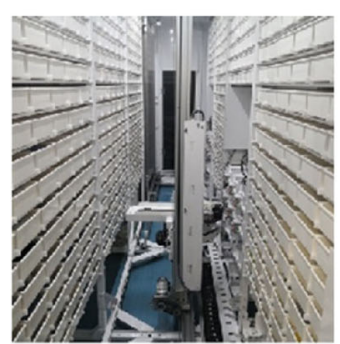

a

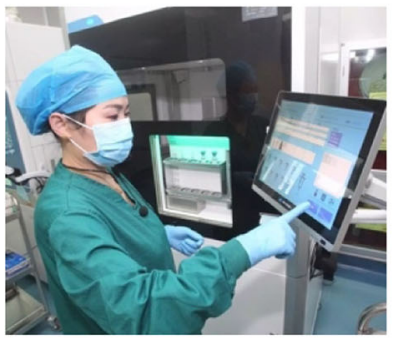

b

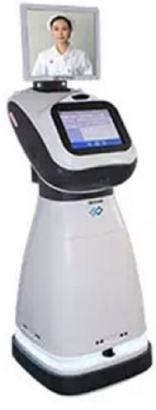

c

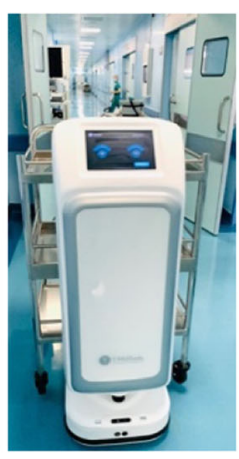

d

Fig. 5 Smart assistant robots (a-d) 


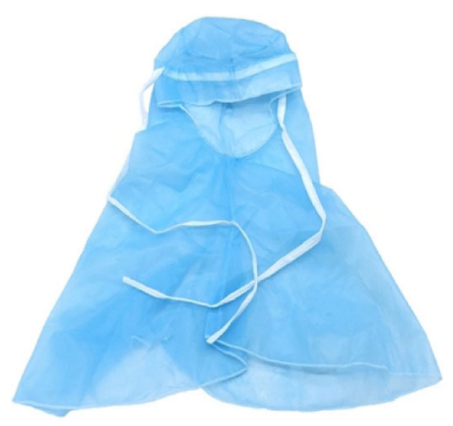

a

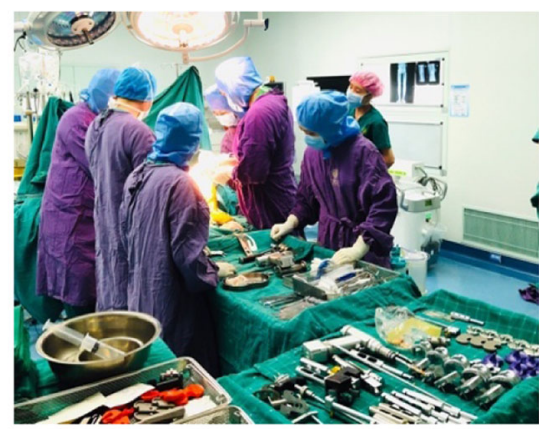

b

Fig. 6 Special hat (a) and TKA intraoperative photo (b)

diagnosis and treatment, clinical management, health care personnel protection, and disinfection were applied soon in our hospital.

National recommendations and local infection control guidelines are tailored to the availability of medical resources, which were imminently adopted to fight against the pandemic $[14,15]$. de Girolamo et al. believe that nonsteroidal anti-inflammatory drugs (NSAIDs) may induce increased sensitivity to more severe clinical features in coronavirus infection [16]. The Department of Oral and Maxillofacial Surgery of Peking University School and Hospital of Stomatology shared their experience. They make proper diagnosis and treatment for patients according to the urgency and severity of the disease and interventions by following the flow chart strictly as well [17]. Luo and Zhong introduced details of Renji experience as for parts of general surgery [18]. Italian urologists recommended on pathways of perioperative care for urological patients undergoing urgent procedures, which may be inspired for urological societies [19]. Anesthesiologists are required to adopt tailored anesthetic practices to individual patients which will ensure the best outcomes [20]. Former researchers provide the views of related diseases, and they believed that strategies were suitable for physicians, which is good for both patients and the perioperative management team.

The health care personnel of department of orthopedics are vulnerable to the infection due to their extensive and close exposure to patients. In consideration of the rapid spread of epidemic, health care staff are at added risk of exposure and infection during the practice of treatment [13]. For the purpose of limiting the quantity of the people and reducing the chance of contacting, physical therapy should be provided only to immediate post-operative patients and some of the other proper patients should be replaced by home exercise programs [21]. The treatment strategy should be changed timely, and appropriate methods should be adopted to minimize the adverse effect of the epidemic in orthopedic diseases' treatment.

It is a difficult task how to maximize the protection for health of medical staff, and the safety of wards and hospitals. In our study, none of staff was infected during the clinical practice. Preserving a highly skilled health care workforce is a top priority for any community and health care system. To avoid the aggravation of COVID-

Table 2 Analysis of patient outcomes between the two periods $(N=96)$

\begin{tabular}{|c|c|c|c|c|c|c|}
\hline \multirow[t]{2}{*}{ Patient outcomes } & \multicolumn{2}{|c|}{$2019(N=50)$} & \multicolumn{2}{|c|}{$2020(N=46)$} & \multirow[t]{2}{*}{$t / x^{2}$} & \multirow{2}{*}{$\begin{array}{l}P \\
\text { value }\end{array}$} \\
\hline & Count & Percentage & Count & Percentage & & \\
\hline Duration (min) & 205.9 & - & 201.3 & - & 0.591 & 0.261 \\
\hline Complications & 6 & $6.25 \%$ & 0 & $0 \%$ & 5.888 & $0.015^{*}$ \\
\hline Re-operation & 4 & $3.13 \%$ & 0 & $0 \%$ & 3.84 & $0.049^{*}$ \\
\hline SSI & 1 & $1.04 \%$ & 1 & $1.04 \%$ & 0.004 & 0.952 \\
\hline System infection & 1 & $1.04 \%$ & 0 & $0 \%$ & 0.93 & 0.335 \\
\hline COVID-19 infection & 0 & $0 \%$ & 0 & $0 \%$ & - & - \\
\hline Mortality & 0 & $0 \%$ & 0 & $0 \%$ & - & - \\
\hline
\end{tabular}

SSI surgical site infection

${ }^{*} p<0.05$, statistically significant 
19 or collapse of the health system, emergency department was emphasized in our hospital and several recommendations were issued to help support health care workers against the pandemic.

For the purpose of control COVID-19, we conclude the experience of our department during the pandemic. First of all, strict and detailed work flow chart could be a clear guidance for medical staff in various situations. Secondly, variable departments should cooperate together for special period to optimize the medical service and improve quality and efficiency. Thirdly, we staff should pay more attention to the construction of hospital artificial intelligence and high technology information such as make full use of the smart assistant tools, which may be a key solution to the prevention and control of the epidemic.

There are several limitations in our study. First, we conducted this retrospective cohort study by using a database in our department within 2 years, particularly with new generation constructs. Prospective studies are needed to validate these calculators and refine over time. Moreover, the database was small and did not include information on long-term follow-up outcomes. Last but not least, the provided flow charts, which may evolve over time, could be used as guidance for health care workers who are involved in the care of patients. When available, we will provide new evidence in further releases of these guidelines and we believe that future studies are necessary to define more flow charts briefly and clearly.

\section{Conclusion}

Our study indicated that medical quality and efficiency were affected little with the help of strategies described above during the epidemic, which could be a reference tool for medical staff in routine clinical practice for admission of patients around the world. What is more, the provided strategies, which may evolve over time, could be used as empirical guidance and reference for orthopedic peers to get through the pandemic and ensure the normal operation of the hospital.

\section{Abbreviations}

BRT: Blood routine examination; CCT: Chest computed tomography; MDT: Multidisciplinary diagnosis and treatment model; COVID19: Coronavirus disease 2019: OR: Operating room; ID card: Identification card; SSI: Surgical site infection; TKA: Total knee arthroplasty; ASA: American Society of Anesthesiologists; NSAIDs: nonsteroidal anti-inflammatory drugs; ARDS: Acute respiratory distress syndrome; MODS: Multi-organ dysfunction

\section{Acknowledgements}

The authors sincerely acknowledge the entire staff of the Department of Bone \& Joint Surgery, Peking University Shenzhen Hospital, who offered their assistance throughout the course of this study.

\section{Authors' contributions}

Guoqing Li and Jian Weng prepared the manuscript. Yifei Yang collected and inputted the data. Chang Xu carried out the statistical analysis and offered the materials. Ao Xiong assisted with the revision of the manuscript.
Deli Wang and Hui Zeng initiated and designed the study. All authors read and approved the final manuscript.

\section{Funding}

This study was supported by grants from the "San-Ming" Project of Medicine in Shenzhen (no. SZSM201612092), Natural Science Foundation of Guangdong Province (no. 2019A1515011290), and Research and Development Projects of Shenzhen (no. JCYJ20170307111755218).

Availability of data and materials

Please contact the author for data requests.

\section{Ethics approval and consent to participate}

Ethical review approval was obtained from the Human Subject Committee at Ethics Committee of Peking University Shenzhen Hospital (Ethics Committee of Peking University Shenzhen Hospital (research) [2020] 013th).

\section{Consent for publication}

Not applicable.

\section{Competing interests}

All of the authors of this paper have disclosed potential or pertinent conflicts of interest, which may include receipt of payment, either direct or indirect; institutional support; or association with an entity in the biomedical field which may be perceived to have potential conflict of interest with the submitted article. Each author certifies that his or her institution approved the human protocol for this investigation and that all investigations were conducted in conformity with ethical principles of research. This work was performed at the Department of Bone \& Joint Surgery, Peking University Shenzhen Hospital, Shenzhen, People's Republic of China.

\section{Author details}

${ }^{1}$ Department of Bone \& Joint Surgery, Peking University Shenzhen Hospital, Shenzhen 518036, People's Republic of China. ${ }^{2}$ National \& Local Joint Engineering Research Center of Orthopaedic Biomaterials, Department of Bone \& Joint Surgery, Peking University Shenzhen Hospital, Shenzhen 518036, People's Republic of China. ${ }^{3}$ Department of Medical Administration, Peking University Shenzhen Hospital, Shenzhen 518036, People's Republic of China.

Received: 1 July 2020 Accepted: 23 September 2020

Published online: 15 October 2020

References

1. Sun P, Lu X, Xu C, Sun W, Pan B. Understanding of COVID-19 based on current evidence. J Med Virol. 2020;92(6):548-51.

2. Huang C, Wang Y, Li X, Ren L, Zhao J, Hu Y, Zhang L, Fan G, Xu J, Gu X, Cheng Z, Yu T, Xia J, Wei Y, Wu W, Xie X, Yin W, Li H, Liu M, Xiao Y, Gao H, Guo L, Xie J, Wang G, Jiang R, Gao Z, Jin Q, Wang J, Cao B. Clinical features of patients infected with 2019 novel coronavirus in Wuhan, China. Lancet. 2020;395(10223):497-506.

3. Chan JF, Yuan S, Kok KH, To KK, Chu H, Yang J, Xing F, Liu J, Yip CC, Poon RW, Tsoi HW, Lo SK, Chan KH, Poon VK, Chan WM, Ip JD, Cai JP, Cheng VC, Chen $\mathrm{H}$, Hui CK, Yuen KY. A familial cluster of pneumonia associated with the 2019 novel coronavirus indicating person-to-person transmission: a study of a family cluster. Lancet. 2020;395(10223):514-23.

4. Chen N, Zhou M, Dong X, Qu J, Gong F, Han Y, Qiu Y, Wang J, Liu Y, Wei Y, Xia J, Yu T, Zhang X, Zhang L. Epidemiological and clinical characteristics of 99 cases of 2019 novel coronavirus pneumonia in Wuhan, China: a descriptive study. Lancet. 2020;395(10223):507-13.

5. Meo SA, Alhowikan AM, Al-Khlaiwi T, Meo IM, Halepoto DM, labal M, Usmani AM, Hajjar W, Ahmed N. Novel coronavirus 2019-nCoV: prevalence, biological and clinical characteristics comparison with SARS-CoV and MERSCoV. Eur Rev Med Pharmacol Sci. 2020;24(4):2012-9.

6. Lim J, Jeon S, Shin HY, Kim MJ, Seong YM, Lee WJ, Choe KW, Kang YM, Lee B, Park SJ. Case of the index patient who caused tertiary transmission of COVID-19 infection in Korea: the application of lopinavir/ritonavir for the treatment of COVID-19 infected pneumonia monitored by quantitative RTPCR. J Korean Med Sci. 2020;35(6):e79.

7. Hong YR, Lawrence J, Williams D Jr, Mainous lii A. Population-level interest and telehealth capacity of US hospitals in response to COVID-19: cross- 
sectional analysis of Google search and national hospital survey data. JMIR Public Health Surveill. 2020;6(2):e18961.

8. Cipollaro L, Giordano L, Padulo J, Oliva F, Maffulli N. Musculoskeletal symptoms in SARS-CoV-2 (COVID-19) patients. J Orthop Surg Res. 2020;15(1):178.

9. Boutis K. The emergency evaluation and management of pediatric extremity fractures. Emerg Med Clin North Am. 2020;38(1):31-59.

10. Skjaker SA, Enger M, Engebretsen L, Brox Jl, Boe B. Young men in sports are at highest risk of acromioclavicular joint injuries: a prospective cohort study. Knee Surg Sports Traumatol Arthrosc. 2020. https://doi.org/10.1007/s00167020-05958-x.

11. Li HC, Ma J, Zhang H, Cheng Y, Wang X, Hu ZW, Li N, Deng XR, Zhang Y, Zheng XZ, Yang F, Weng HY, Dong JP, Liu JW, Wang YY, Liu XM. Thoughts and practice on the treatment of severe and critical new coronavirus pneumonia. Zhonghua Jie He He Hu Xi Za Zhi. 2020;43(0):E038.

12. Zangrillo A, Beretta L, Silvani P, Colombo S, Scandroglio AM, Dell'Acqua A, Fominskiy E, Landoni G, Monti G, Azzolini ML, Monaco F, Oriani A, Belleti A, Sartorelli M, Pallanch O, Saleh O, Sartini C, Nardelli P, Lombardi G, Morselli F, Scquizzato T, Frontera A, Ruggeri A, Scotti R, Assanelli A, Dagna L, RovereQuerini P, Castagna A, Scarpellini P, Di Napoli D, Ambrosio A, Ciceri F, Tresoldi $\mathrm{M}$. Fast reshaping of intensive care unit facilities in a large metropolitan hospital in Milan, Italy: facing the COVID-19 pandemic emergency. Crit Care Resusc. 2020;22(2):91-4.

13. Givi B, Schiff BA, Chinn SB, Clayburgh D, lyer NG, Jalisi S, Moore MG, Nathan CA, Orloff LA, O'Neill JP, Parker N, Zender C, Morris LGT, Davies L. Safety recommendations for evaluation and surgery of the head and neck during the COVID-19 pandemic. JAMA Otolaryngol Head Neck Surg. 2020;146(6): 579-84

14. Conti P, Gallenga CE, Tete G, Caraffa A, Ronconi G, Younes A, Toniato E, Ross R, Kritas SK. How to reduce the likelihood of coronavirus-19 (CoV-19 or SARS-CoV-2) infection and lung inflammation mediated by IL-1. J Biol Regul Homeost Agents. 2020;34(2):333-8.

15. Rengasamy S, Eimer B, Shaffer RE. Simple respiratory protection--evaluation of the filtration performance of cloth masks and common fabric materials against 20-1000 nm size particles. Ann Occup Hyg. 2010;54(7):789-98.

16. de Girolamo L, Peretti GM, Maffulli N, Brini AT. Covid-19-the real role of NSA Ds in Italy. J Orthop Surg Res. 2020;15(1):165.

17. Yang Y, Soh HY, Cai ZG, Peng X, Zhang Y, Guo CB. Experience of diagnosing and managing patients in oral maxillofacial surgery during the prevention and control period of the new coronavirus pneumonia. Chin J Dent Res. 2020;23(1):57-62

18. Luo Y, Zhong M. Standardized diagnosis and treatment of colorectal cancer during the outbreak of novel coronavirus pneumonia in Renji hospital. Zhonghua Wei Chang Wai Ke Za Zhi. 2020;23(3):E003.

19. Simonato AG, Giannarini $G$, Abrate A, Bartoletti R, Crestani A, De Nunzio C Gregori A, Liguori G, Novara G, Pavan N, Trombetta C, Tubaro A, Porpiglia F, Ficarra V. Clinical pathways for urology patients during the COVID-19 pandemic. Minerva Urol Nefrol. 2020;72(3):376-83.

20. Lie SA, Wong SW, Wong LT, Wong TGL, Chong SY. Practical considerations for performing regional anesthesia: lessons learned from the COVID-19 pandemic. Can J Anaesth. 2020. https://doi.org/10.1007/s12630-020-01637-0.

21. Alturkistany A, Abduljabbar FH, Alhelal F, Dajim NB, Khalifah S, Konbaz F, Aleissa S, Al-Habib A, Kattan M, Alqahtani Y, Alatassi R. The Saudi Spine Society guidelines on spinal surgery during the COVID-19 pandemic. J Orthop Surg Res. 2020;15(1):211.

\section{Publisher's Note}

Springer Nature remains neutral with regard to jurisdictional claims in published maps and institutional affiliations.

Ready to submit your research? Choose BMC and benefit from:
- fast, convenient online submission
- thorough peer review by experienced researchers in your field
- rapid publication on acceptance
- support for research data, including large and complex data types
- gold Open Access which fosters wider collaboration and increased citations
- maximum visibility for your research: over 100M website views per year
At BMC, research is always in progress.
Learn more biomedcentral.com/submissions

